\title{
The Performance of Carbon Fibre Composites as ICCP Anodes for Reinforced Concrete Structures
}

\author{
Chinh Van Nguyen, ${ }^{1}$ Paul Lambert, ${ }^{1}$ Pal Mangat, ${ }^{1}$ Fin O'Flaherty, ${ }^{1}$ and Graeme Jones ${ }^{2}$ \\ ${ }^{1}$ Centre for Infrastructure Management, Materials and Engineering Research Institute, Sheffield Hallam University, \\ Sheffield S1 1WB, UK \\ ${ }^{2}$ C-Probe Systems Ltd., Blackmoss Court, Blackmoss Road, Dunham Massey, Cheshire WA145RG, UK \\ Correspondence should be addressed to Chinh Van Nguyen, chinhxla@gmail.com
}

Received 31 October 2012; Accepted 19 November 2012

Academic Editors: N. Boshkov, E. D’Elia, and C. Valentini

Copyright (๑) 2012 Chinh Van Nguyen et al. This is an open access article distributed under the Creative Commons Attribution License, which permits unrestricted use, distribution, and reproduction in any medium, provided the original work is properly cited.

Cathodic protection has been proven to be one of the most widely applicable and cost-effective solutions for tackling steel corrosion in reinforced concrete. In this study, the possible use of carbon fibre composites, which are primarily used to strengthen concrete members, has been investigated as impressed current cathodic protection anodes. Carbon fibre anodes have been assessed in both concrete and calcium hydroxide solution. Two bonding mediums incorporating epoxy and geopolymer have also been investigated. The results demonstrate that epoxy resin can be used for bonding carbon fibre fabric anodes to reinforced concrete structures while geopolymer is more effective for bonding carbon fibre reinforced polymer (CFRP) rod into preformed grooves in the concrete surface. The dissolution of carbon fibre anode appears to stablise after a period of time, dependent upon the size and shape of the anode and applied voltage and current. Based on the present results, a maximum current density of $128 \mathrm{~mA} / \mathrm{m}^{2}$ of reinforcing steel area is recommended for the operation of CFRP fabric anode and $64 \mathrm{~mA} / \mathrm{m}^{2}$ of reinforcing steel area for that of CFRP rod anode.

\section{Introduction}

Cathodic protection $(\mathrm{CP})$ is a proven method of controlling corrosion in reinforced concrete through the application of a small DC current [1-4]. This can be applied either galvanically (e.g., by the preferential corrosion of zinc) or by an inert anode, referred to as impressed current cathodic protection (ICCP) [5-9]. In atmospherically exposed reinforced concrete structures, the successful application of ICCP depends significantly upon the selection of appropriate anode systems $[10,11]$. There are a number of anode systems currently available; these include: conductive carbon loaded paints, thermal sprayed zinc, coated titanium expanded mesh or mesh ribbon in a concrete overlay, coated titanium expanded mesh ribbon mortared into slots chased into the concrete, internal (discrete) anode, and conductive cementitious overlay containing nickel plated carbon fibre $[11,12]$. The properties of the anode materials need to be considered and researched carefully to ensure they operate effectively during their required service life.

Cathodic protection systems require a level of monitoring, generally by reference electrodes, to assess how well the system is controlling corrosion. For ICCP systems in reinforced concrete, the current can be adjusted to the appropriate value to protect the steel reinforcement [13]. The effectiveness of ICCP depends greatly on the correct operation of the anodes, their electrical conductivity for electrochemical process, and their service life or rate of consumption due to a number of environmental and operational factors. The anode system is required to deliver sufficient current in order to provide adequate protection for the structures. Therefore selecting the appropriate value of current contributes significantly to the minimisation or avoidance of damage to the anodes due to excessive consumption, passivation or loss of bond with the concrete.

Carbon fibre composites as civil engineering materials are a relatively recent development. They have previously been used in a wide range of mostly "hi-tech" industries [1416]. It has been documented that CFRP can be applied on the surface of concrete with little environmental degradation and that CFRP wraps can, on their own, impede further corrosion of steel [17-21]. CFRP is an electrically conductive material; however, only limited research has been carried out 


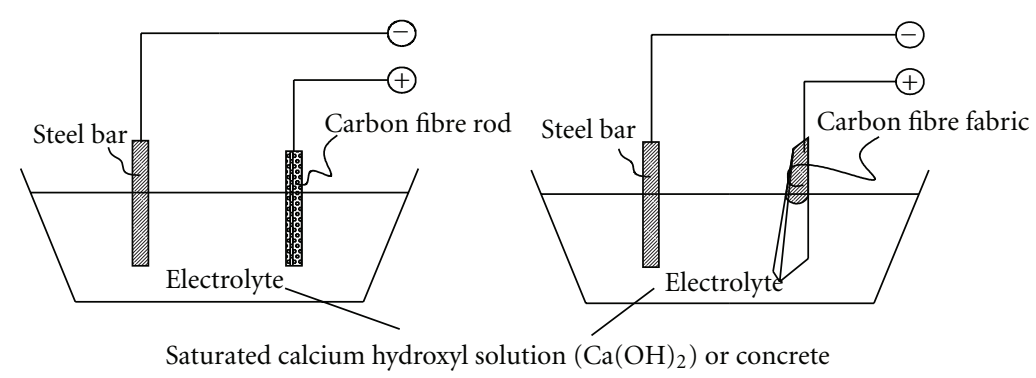

FIGURE 1: Test arrangements for the carbon fibre anodes (rod and fabric) in saturated $\mathrm{Ca}(\mathrm{OH})_{2}$ and concrete electrolytes.

with respect to the electrical conductivity of carbon fibre and the possibility of using such materials in the protection of steel from corrosion. Therefore, this paper evaluates the electrical conductivity and other properties of CFRP when employed as an anode in an ICCP system. The bonding medium used to embed the carbon fibre into the concrete has also been investigated.

\section{Experimental Method}

\subsection{Materials}

2.1.1. Epoxy Adhesive. The epoxy adhesive was supplied by Sika Corporation (US). In this test, Sikadur300 adhesive was used, which is a two-component $100 \%$ solids, moisturetolerant, high strength, high modulus epoxy widely used in CFRP strengthening applications. It is documented by the manufacturer that Sikadur300 is used as a seal coat and impregnating resin for horizontal and vertical applications.

2.1.2. Geopolymer. A commercially available geopolymer developed at Sheffield Hallam University was used to bond the CFRP rods to the grooved reinforced concrete beams. Chopped carbon fibres were added to the geopolymer at $1.5 \%$ of volume in order to control shrinkage and increase the electrical conductivity of the mix. The compressive strengths of different compositions of geopolymer which were tested ranged from $44.4 \mathrm{MPa}$ to $52.0 \mathrm{MPa}$ at 28 days age.

2.1.3. Carbon Fibre. A high strength, unidirectional carbon fibre fabric (type Sika Wrap Hex 103C, supplied in the UK by C-Probe Systems Ltd.) was used. In normal applications, the material is field laminated using epoxy resin to form a carbon fibre reinforced polymer for the strengthening of concrete structures.

Carbon fibre rod (type Sika CarboDur, supplied in the UK by C-Probe Systems Ltd.) was also used which is designed for strengthening concrete, timber, and masonry structures. The rods have very high strength, light weight, high modulus of elasticity, are non-corrosive, and display excellent fatigue resistance.

\subsection{Test Arrangement}

2.2.1. Test in $\mathrm{Ca}(\mathrm{OH})_{2}$ and Concrete Electrolyte. A series of tests was established in which carbon fibre was employed as an ICCP anode with a range of DC voltages applied. The aim was to identify the optimum range of currents that could provide adequate protection to the steel reinforcement without causing significant damage to the carbon fibre anode. Prior to conducting the tests, both the carbon fibre anode and steel bars were weighed and then subsequently reweighed at the end of the test. The ICCP was established with the DC positive terminal connected to the carbon fibre anode while the DC negative terminal was connected to the steel bars.

The DC voltage was maintained at $5 \mathrm{~V}, 10 \mathrm{~V}$, or $20 \mathrm{~V}$. The tests were run in the ambient laboratory environment (temperature $20^{\circ} \mathrm{C}, \mathrm{RH}=60 \pm 5 \%$ ). The performance of carbon fibre anodes was evaluated by visual monitoring, applied current and circuit resistance of the electrolyte with time. The schematic test arrangement is shown in Figure 1. The test programme for carbon fibre anodes in saturated calcium hydroxyl solution and in concrete is detailed in Table 1.

\subsubsection{Test for Carbon Fibre Anodes with respect to the Electrical} Conductivity of the Bonding Medium. A variant of the carbon fibre anode test was further developed by the use of small scale specimens in which carbon fibre rod or fabric was bonded to concrete by epoxy (Specimens 4.1, 4.2a and 4.2b) or by a non-resinous geopolymer (Specimens 4.2c), see Figure 2. Four reinforced concrete prisms with dimensions of $250 \times 100 \times 100 \mathrm{~mm}$ were cast. After 7 days of curing in a standard laboratory environment (temperature $20^{\circ} \mathrm{C}, \mathrm{RH}=$ $60 \pm 5 \%$ ), one of the four concrete prisms had carbon fibre fabric applied to one face using epoxy resin. The other three prisms had a carbon fibre rod grouted into a pre-cut groove. The steel bars in the prisms were connected to the negative terminal of a DC supply while the carbon fibre rod or fabric anodes were connected to the positive terminal. These tests were employed to evaluate the effectiveness of carbon fibre anodes with respect to the electrical conductivity of the bonding medium (epoxy and geopolymer), as well as the bond strength at the concrete and carbon fibre interface. The test programme for carbon fibre anodes bonded to concrete using epoxy or geopolymer is shown in Table 2.

The continuous electrical conductivity of the carbon fibre anodes used in combination with the epoxy adhesive or geopolymer was assessed by visual monitoring, applied current, and circuit resistance of the electrolyte with time. The electrochemical performance of the CF rod or fabric anode was assessed in terms of the current or corresponding $\mathrm{CP}$ circuit resistance required to maintain a constant voltage 
TABLE 1: Test programme of carbon fibre anode in saturated $\mathrm{Ca}(\mathrm{OH})_{2}$ and concrete electrolyte.

\begin{tabular}{|c|c|c|c|c|}
\hline Specimen & Electrolyte & ID & Total surface area $\left(\mathrm{cm}^{2}\right)$ & Voltage applied (V) \\
\hline \multirow{2}{*}{1.1} & \multirow{2}{*}{$\mathrm{Ca}(\mathrm{OH})_{2}$} & Steel 1 & 37.7 & \multirow{2}{*}{10} \\
\hline & & CFRP rod 1 & 37.7 & \\
\hline \multirow{2}{*}{1.2} & \multirow{2}{*}{$\mathrm{Ca}(\mathrm{OH})_{2}$} & Steel 2 & 37.7 & \multirow{2}{*}{10} \\
\hline & & CFRP fabric 2 & $400 \mathrm{k}^{*}$ & \\
\hline \multirow{2}{*}{2.1} & \multirow{2}{*}{$\mathrm{Ca}(\mathrm{OH})_{2}$} & Steel 3 & 37.7 & \multirow{2}{*}{20} \\
\hline & & CFRP rod 3 & 37.7 & \\
\hline \multirow{2}{*}{2.2} & \multirow{2}{*}{$\mathrm{Ca}(\mathrm{OH})_{2}$} & Steel 4 & 37.7 & \multirow{2}{*}{5} \\
\hline & & CFRP fabric 4 & $487.5 \mathrm{k}^{*}$ & \\
\hline \multirow{2}{*}{3.1} & \multirow{2}{*}{ Concrete } & Steel 5 & 43.96 & \multirow{2}{*}{10} \\
\hline & & CFRP rod 5 & 43.96 & \\
\hline \multirow{2}{*}{3.2} & \multirow{2}{*}{ Concrete } & Steel 6 & 43.96 & \multirow{2}{*}{10} \\
\hline & & CFRP fabric 6 & $840 \mathrm{k}^{*}$ & \\
\hline
\end{tabular}

$* \mathrm{k}$ is a constant that takes account of the difference between the real and apparent surface area of the CFRP fabric (see Section 3.2).
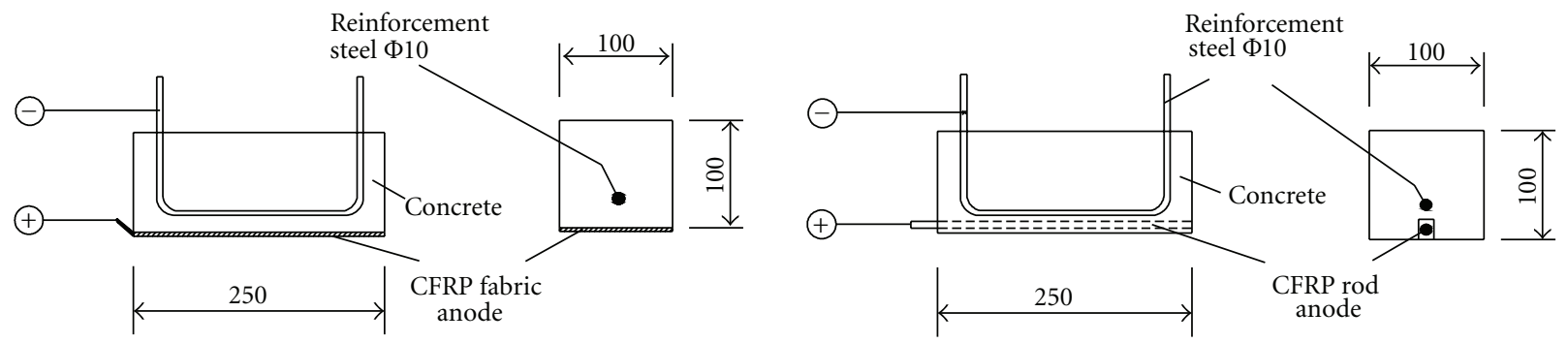

FIGURE 2: Schematic test of electrical conductivity of carbon fibre fabric or rod bonded to concrete by different media.

between the steel cathode and carbon fibre anode. During operation of the ICCP, the voltage was maintained at $5 \mathrm{~V}$ or $10 \mathrm{~V}$ (see Table 2) while the current applied to the anode was monitored.

2.2.3. Application of Carbon Fibre Working as ICCP Anode to Small Beams. Two pre-corroded reinforced concrete beams $(150 \times 100 \times 900$, see [22] $)$ were cathodically protected using CF fabric anodes (CFF1 and CFF2) while two others were cathodically protected using CF rod anodes (CFR1 and CFR2). The CF fabric anodes were bonded to the concrete surface using epoxy. The CF rod anodes were grooved into the concrete beams using geopolymer and chopped carbon fibre. ICCP was applied to the corroded reinforced concrete beams by connecting the reinforcing steel to the negative terminal and the CFRPs anode to the positive terminal of the multi-channel DC power supply. Testing was conducted in a laboratory environment (temperature $20^{\circ} \mathrm{C}, \mathrm{RH}=60 \pm 5 \%$ ) in which the resistivity of the concrete is relatively high (Figure 3). The applied currents were $10 \mathrm{~mA}$ (corresponding to $128.4 \mathrm{~mA} / \mathrm{m}^{2}$ of steel area) for CF fabric anode and $5 \mathrm{~mA}$ (corresponding to $64.2 \mathrm{~mA} / \mathrm{m}^{2}$ of steel area) for CF rod anode which corresponded to the rest potential of steel reinforcement. The ICCP systems were operated for 1100 hours. The current was checked and the on and instant-off potential values for the embedded steel were recorded daily [22].

\section{Result and Discussion}

\subsection{Visual Monitoring and Mass Loss}

3.1.1. Test in $\mathrm{Ca}(\mathrm{OH})_{2}$ and Concrete Electrolyte. The performance of both the carbon fibre fabric and rod was observed daily during the tests. In each test with the saturated calcium hydroxide solution electrolyte, hydrogen evolution was observed at the cathode (steel bar). Simultaneously, it was observed that the carbon fibre anodes (fabric and rod) suffered from dissolution (Figure 4).

The steel bars and carbon fibre rod and fabric were subsequently washed, dried and reweighed to establish their weight losses, as shown in Table 3 (test durations, in hours, are also given). The weight of steel bars after testing was measured after removal of the calcarious layer deposited onto them by the action of the cathodic polarisation. The results in Table 3 show that the weight loss of the carbon fibre rod anodes is $0.51 \%, 0.56 \%$, and $0.33 \%$ for Specimens $1.1,2.1$, and 3.1 , respectively. The weight loss of the carbon fibre fabric anodes is $2.69 \%, 1.46 \%$, and $0.66 \%$ for Specimens 1.2 , 2.2 , and 3.2, respectively. It can also be seen from the Table 3 that the weight loss of the steel bars in all test specimens is naturally at or around zero.

At the time corresponding to a cumulative current of $13 \mathrm{~mA}$ applied to the carbon fibre rod anode (Specimens 
TABLE 2: Test programme for carbon fibre anodes with respect to the electrical conductivity of the bonding medium.

\begin{tabular}{|c|c|c|c|c|}
\hline Specimens & ID & Bonding medium & Total surface area $\left(\mathrm{cm}^{2}\right)$ & Voltage applied (V) \\
\hline \multirow{2}{*}{4.1} & Steel 7 & \multirow{2}{*}{ Epoxy } & 157.0 & \multirow{2}{*}{5} \\
\hline & Fabric & & $420 \mathrm{k}^{*}$ & \\
\hline \multirow{2}{*}{$4.2 \mathrm{a}$} & Steel 8 & \multirow{2}{*}{ Epoxy } & 157.0 & \multirow{2}{*}{10} \\
\hline & Rod & & 94.2 & \\
\hline \multirow{2}{*}{$4.2 \mathrm{~b}$} & Steel 9 & \multirow{2}{*}{ Epoxy + chopped carbon fibres } & 157.0 & \multirow{2}{*}{10} \\
\hline & Rod & & 94.2 & \\
\hline \multirow{2}{*}{$4.2 \mathrm{c}$} & Steel 10 & \multirow{2}{*}{ Geopolymer + chopped carbon fibres } & 157.0 & \multirow{2}{*}{10} \\
\hline & Rod & & 94.2 & \\
\hline
\end{tabular}

${ }^{*} \mathrm{k}$ is a constant that takes account of the difference between the real and apparent surface area of the CFRP fabric (see Section 3.2).

TABLE 3: Mass loss of carbon fibre anodes and steel bar cathodes_-test in $\mathrm{Ca}(\mathrm{OH})_{2}$ and concrete electrolyte.

\begin{tabular}{|c|c|c|c|c|c|c|}
\hline \multirow{2}{*}{ Specimen } & \multirow{2}{*}{ Electrolyte } & \multirow{2}{*}{ ID } & \multicolumn{2}{|c|}{ Weight } & \multirow{2}{*}{$\begin{array}{c}\text { Weight loss } \\
(\%)\end{array}$} & \multirow{2}{*}{$\begin{array}{c}\text { Test duration } \\
\text { (hours) }\end{array}$} \\
\hline & & & $\begin{array}{l}\text { Before test } \\
(\mathrm{g})\end{array}$ & $\begin{array}{l}\text { After test } \\
(\mathrm{g})\end{array}$ & & \\
\hline \multirow{2}{*}{1.1} & \multirow{2}{*}{$\mathrm{Ca}(\mathrm{OH})_{2}$} & Steel 1 & 66.80 & 66.80 & 0.00 & \multirow{2}{*}{165.5} \\
\hline & & CFRP rod 1 & 17.52 & 17.43 & 0.51 & \\
\hline \multirow{2}{*}{1.2} & \multirow{2}{*}{$\mathrm{Ca}(\mathrm{OH})_{2}$} & Steel 2 & 67.51 & 67.50 & 0.01 & \multirow{2}{*}{165.5} \\
\hline & & CFRP fabric 2 & 4.83 & 4.70 & 2.69 & \\
\hline \multirow{2}{*}{2.1} & \multirow{2}{*}{$\mathrm{Ca}(\mathrm{OH})_{2}$} & Steel 3 & 67.21 & 67.19 & 0.03 & \multirow{2}{*}{249.0} \\
\hline & & CFRP rod 3 & 17.78 & 17.68 & 0.56 & \\
\hline \multirow{2}{*}{2.2} & \multirow{2}{*}{$\mathrm{Ca}(\mathrm{OH})_{2}$} & Steel 4 & 66.70 & 66.66 & 0.06 & \multirow{2}{*}{249.0} \\
\hline & & CFRP fabric 4 & 6.13 & 6.04 & 1.47 & \\
\hline \multirow{2}{*}{3.1} & \multirow{2}{*}{ Concrete } & Steel 5 & 82.73 & 82.73 & 0.00 & \multirow{2}{*}{888.0} \\
\hline & & CFRP rod 5 & 21.12 & 21.05 & 0.33 & \\
\hline \multirow{2}{*}{3.2} & \multirow{2}{*}{ Concrete } & Steel 6 & 82.34 & 82.34 & 0.00 & \multirow{2}{*}{888.0} \\
\hline & & CFRP fabric 6 & 9.50 & 9.44 & 0.63 & \\
\hline
\end{tabular}

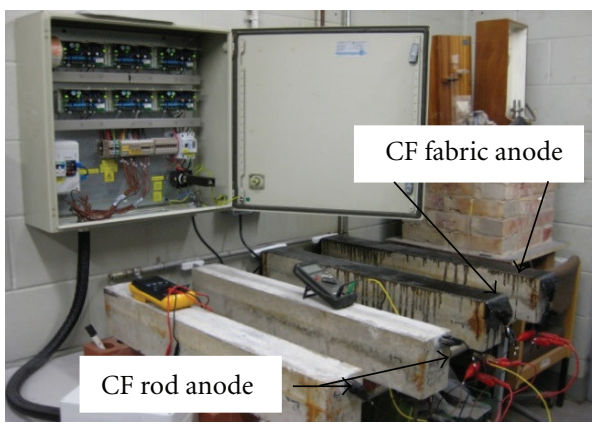

Figure 3: Application of ICCP CF anode to corroded reinforced concrete beams.

3.1 and 3.2), a gaseous and yellow liquid deposit appeared around the rod. The $\mathrm{pH}$ of this material was in the range of 1 to 2 , confirming it is highly acidic. Concrete Society Technical Report number 73 states that acid and oxygen is generated during operation at the surface of anodic materials commonly used for the cathodic protection of reinforced concrete due to the electrochemical reactions. It has been suggested that some anodes may also generate chloride depending on the environment [12]. Therefore, the yellow discharge observed at the carbon fibre rod anode and concrete interface is believed to result from both acid generation and the $3.5 \% \mathrm{NaCl}$ (by weight of cement) which was added to the concrete mix. To confirm this, the deposit was analysed using semi-quantitative XRF which showed that the deposit was around $60 \%$ chloride. The carbon fibre fabric and rod anode after testing are shown in Figure 5.

\subsubsection{Test for Carbon Fibre Anodes with respect to the Electrical} Conductivity of the Bonding Medium. The performance of the CF rod and fabric anodes was monitored and reported in Specimens 4.1, 4.2a, 4.2b, and 4.2c. In the case of the CF fabric, a gaseous and yellow liquid deposit again appeared on the surface of the fabric, which may in turn be reducing the bond at the concrete-fabric interface. In comparison, there was no sign of debonding at the CF rod/geopolymer interface due to the electrochemical reaction. However, a fine crack was observed at the concrete-geopolymer interface.

3.1.3. Carbon Fibre Working as ICCP Anodes to Small Beams. After 985 hours of operation of the ICCP, a small gaseous and yellow liquid deposit appeared on the surface of the CF 

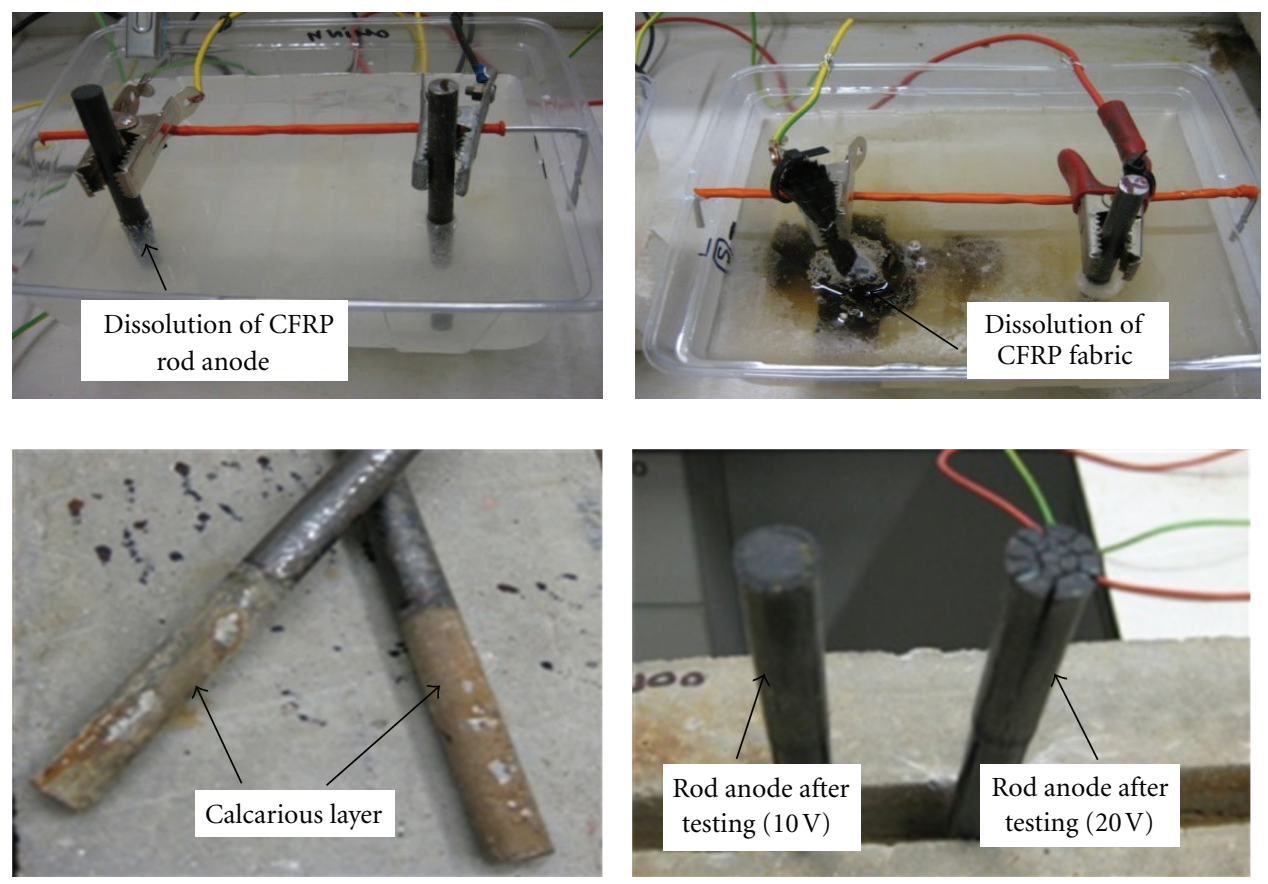

FIgure 4: Performance of steel and carbon fibre anodes in saturated $\mathrm{Ca}(\mathrm{OH})_{2}$ electrolyte.
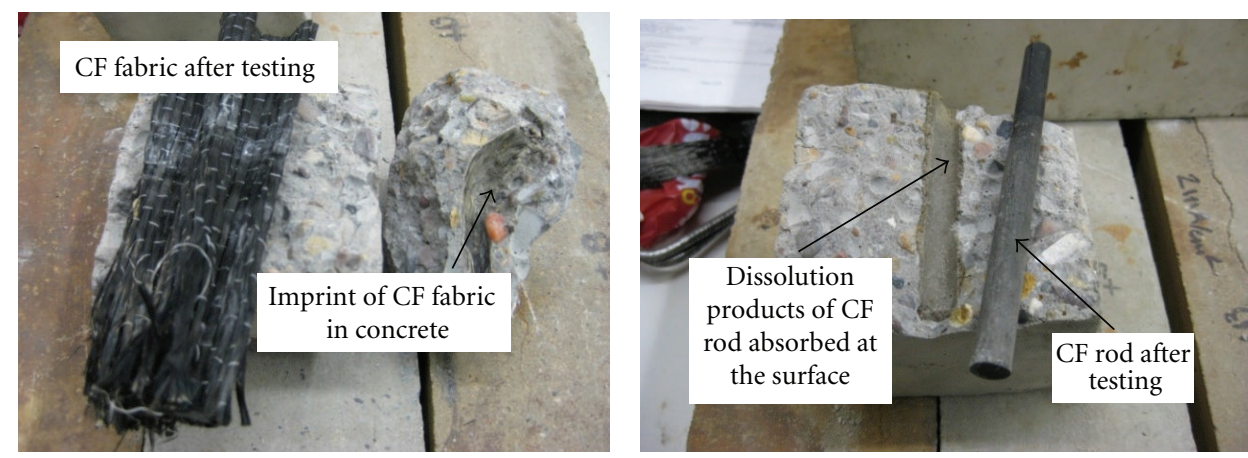

Figure 5: Performance of carbon fibre (CF) anodes in concrete.

fabric anode (Specimens CFF1, CFF2). This could, if more widespread, result in the debonding of the CFRP fabric from the concrete interface. In the case of the CF rod (Specimens CFR1, CFR2), there was no sign of damage or debonding problems [22].

3.2. The Electrochemical Performance of CFRP Anode. The performance of an ICCP anode is represented by a number of parameters including consumption rate (the rate in mass of anode consumed per ampere of current per year), efficiency (a comparison of actual anode mass consumed to the theoretical mass required), steel polarization and $\mathrm{CP}$ circuit resistance (CR) [13].

$\mathrm{CP}$ circuit resistance at time $t$ is simply the quotient of the voltage, $V(t)$ (volts), between the steel cathode and the anode and the CP current density, $J(t)$, as in [13]:

$$
\mathrm{CR}(t)=\frac{V(t)}{J(t)} \quad\left(\text { ohms } \cdot \mathrm{m}^{2}\right) .
$$

It is a DC measurement. While interfacial polarization effects contribute to $\mathrm{CR}$, the changes that occur in $\mathrm{CR}$ with time are expected to be largely related to resistive elements in the $\mathrm{CP}$ system and these elements would be the same whether measured by DC or AC techniques.

The equivalent circuit resistance between carbon fibre anodes and steel cathodes in concrete consist of the anode resistance at the anode-concrete interface, the electrolyte at the steel/concrete interface, and the steel bar resistance. The circuit resistance can be calculated as follows.

The current from the carbon fibre fabric anode passes through the electrolyte to the cathode. The area of contact between the carbon fibre fabric anode and the electrolyte provides the passage for the current. This area is not simply the plan surface area $\left(S_{s}\right)$ since the mesh of the fabric has an influence on the contact area. Therefore, the actual contact surface area of the anode is assumed as the plan surface area $S_{s}$ multiplied by $k$, where $k$ is a constant value that 


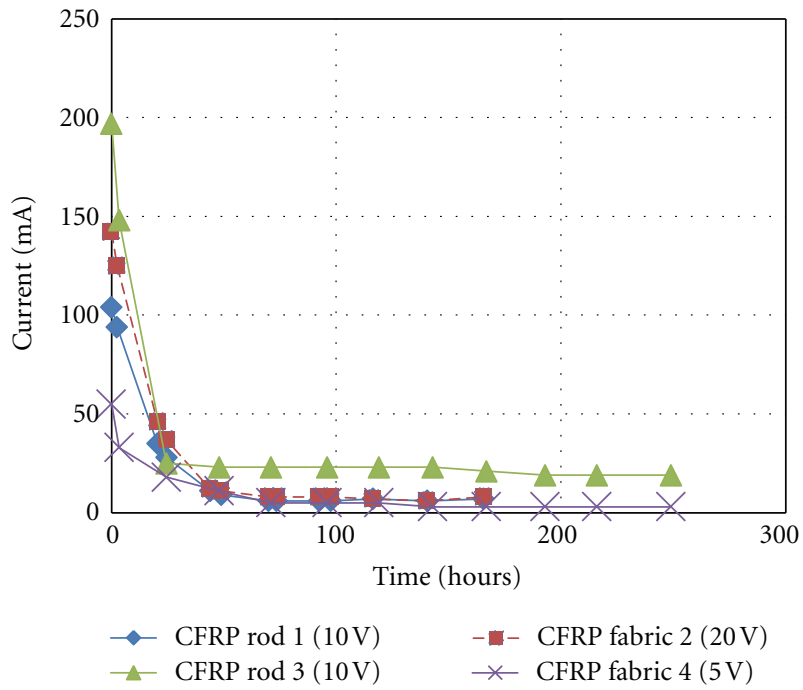

Figure 6: Applied current versus exposure time $\left(\mathrm{Ca}(\mathrm{OH})_{2}\right.$ electrolyte).

takes account of the difference between the real and apparent surface area. For the purpose of analysis and simplicity in this paper, it is not required to calculate an actual value for $k$.

From (1), circuit resistance $\mathrm{CR}=$ voltage $/ \mathrm{CP}$ current density:

$$
\begin{aligned}
& \text { CF rod : } \mathrm{CR}=\frac{V}{I / S_{\text {rod }}}=\frac{V \cdot S_{\text {rod }}}{I}, \\
& \text { CF fabric : } \mathrm{CR}=\frac{V}{I / k S_{s}}=\frac{V \cdot k S_{s}}{I} .
\end{aligned}
$$

3.2.1. Test in $\mathrm{Ca}(\mathrm{OH})_{2}$ and Concrete Electrolyte. The applied current versus exposure time and circuit resistance versus exposure time relationships for different specimens are plotted in Figures 6, 7, 8 and 9.

It can be seen from Figure 6 that as the exposure time increases, the current passing to both the CF rod and fabric anodes reduced significantly in the first of 50 hours from $104 \mathrm{~mA}$ to $9 \mathrm{~mA}$ and $142 \mathrm{~mA}$ to $11 \mathrm{~mA}$ for Rod 1 and Fabric 2 , respectively. When operated at $20 \mathrm{~V}$ the current passing to Rod 3 anode decreased dramatically from $197 \mathrm{~mA}$ to $25 \mathrm{~mA}$ after 24.5 hours of exposure, with a further reduction to $19 \mathrm{~mA}$ at which it appeared to stabilise. Even when operated at $5 \mathrm{~V}$ the Fabric 4 current dropped from $55 \mathrm{~mA}$ to $5 \mathrm{~mA}$ in the first 71 hours, and continued to fall to $3 \mathrm{~mA}$ after 143 hours, where it remained stable until the test was terminated at 249 hours. This is attributed to the dissolution of the CF rod or fabric anode into the calcium hydroxyl solution, causing an increase in resistance.

Figure 7 presents the applied current versus exposure time of CF rod 5 and CF fabric 6 in concrete electrolyte. The current passing to both Rod 5 and Fabric 6 anodes reduced from $20 \mathrm{~mA}$ to $9 \mathrm{~mA}$ and from $23 \mathrm{~mA}$ to $10 \mathrm{~mA}$ respectively in the first of 96 hours. The current continuously decreased to $1 \mathrm{~mA}$ for Rod 5 anode and to $2 \mathrm{~mA}$ for Fabric 6 anode after 888 hours. This is attributed to the high resistivity of the

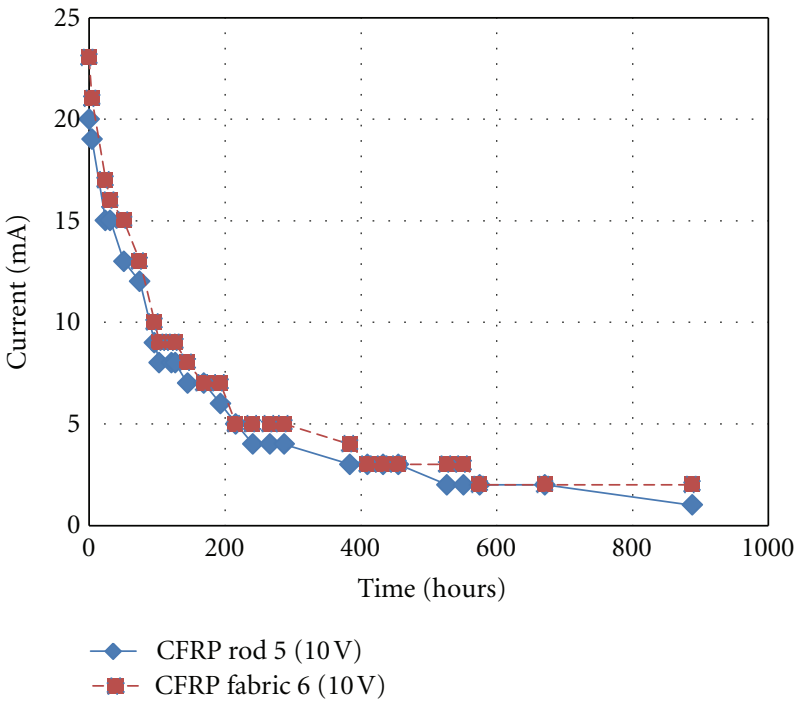

Figure 7: Applied current versus exposure time (concrete electrolyte).

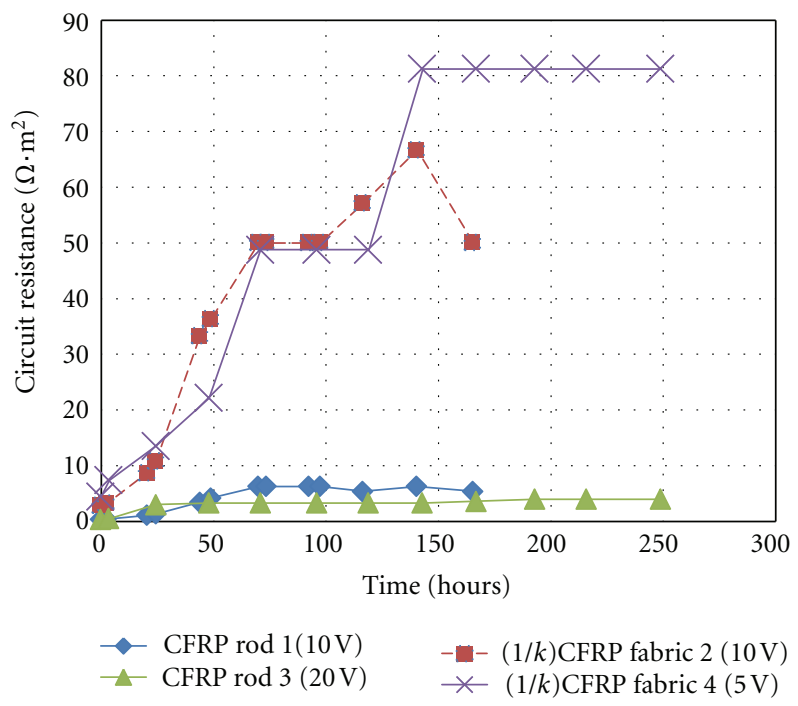

FIgURE 8: The circuit resistance versus exposure time $\left(\mathrm{Ca}(\mathrm{OH})_{2}\right.$ electrolyte).

concrete electrolyte, with the possible dissolution of carbon fibre apparently not significantly affecting the resistance of the electrolyte. After an initial period of operation, the current passing remained constant and the rate of dissolution of the CF rod and fabric anodes was relatively low. Therefore, the currents passing remained relatively unchanged due to the stable resistance. It would, therefore, appear that the CF rod and fabric anodes reach a stable state after a specific time, dependent upon the type of anode and electrolyte. It is also noted that the rate of dissolution of CF anode depends on both the magnitude of voltage applied and the type of CF anode employed.

Figure 8 shows the circuit resistance versus exposure time relationships for specimen 1.1, 1.2, 2.1, and 2.2. The Rod 1 anode circuit resistance increased moderately in 


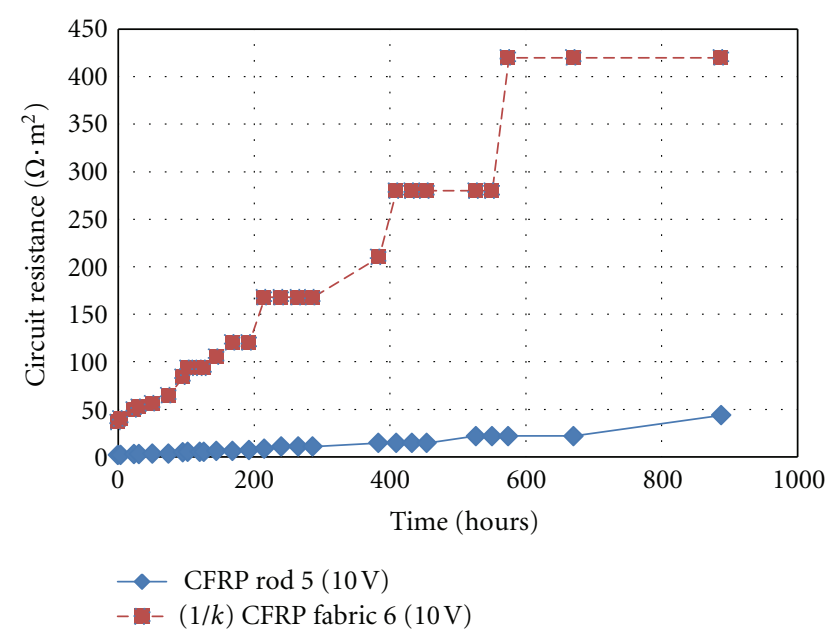

FIgURE 9: The circuit resistance versus exposure time (concrete electrolyte).

the first period of 70 hours from $0.4 \Omega \cdot \mathrm{m}^{2}$ to $6.3 \Omega \cdot \mathrm{m}^{2}$. Thereafter, circuit resistance remained fairly constant at around $5.4 \Omega \cdot \mathrm{m}^{2}$ to $6.3 \Omega \cdot \mathrm{m}^{2}$. However, for Fabric 2 anode, the circuit resistance rose significantly in the first period of 70 hours from $2.8 \mathrm{k} \Omega \cdot \mathrm{m}^{2}$ to $50 \mathrm{k} \Omega \cdot \mathrm{m}^{2}$ and achieved the highest value of $66.7 \mathrm{k} \Omega \cdot \mathrm{m}^{2}$ after 140.5 hours of exposure. In addition, after 165.5 hours exposure, the mass loss of Fabric 2 anode was $2.69 \%$ compared to $0.51 \%$ for the Rod 1 anode. Therefore, it can be concluded that the rate of dissolution of the CF fabric was significantly higher than that of the CF rod for the same period. This may be due to the exposure areas of the CF fabric in the electrolyte solution being much greater than that of the CF rod. Also the circuit resistance in the case of Fabric 4 anode increased dramatically in the first 71 hours of operation from $4.4 \mathrm{k} \Omega \cdot \mathrm{m}^{2}$ to $48.8 \mathrm{k} \Omega \cdot \mathrm{m}^{2}$ and remained constant for a further 48 hours before rising again to $81.3 \mathrm{k} \Omega \cdot \mathrm{m}^{2}$ after 249 hours, presumably due to dissolution of the CF fabric. By contrast, the circuit resistance of Rod 3 anode increased only slightly to $4 \Omega \cdot \mathrm{m}^{2}$ after 249 hours. It can be seen that CF fabric dissolved much more than the CF rod, despite the voltage applied to CF fabric being lower. However, it should be noted that the CF rod anode suffered significant damage (see Figure 4). Therefore, the magnitude of voltage applied to the anode needs to be considered carefully in order to avoid damage to the anodes.

Figure 9 shows the circuit resistance versus exposure time relationships for Specimens 3.1 and 3.2. The circuit resistance of Rod 5 anode has risen steadily from $2.2 \Omega \cdot \mathrm{m}^{2}$ to $43.96 \Omega \cdot \mathrm{m}^{2}$. The trend of increasing circuit resistance in the case of Fabric 6 anode is also observed. As previously discussed, it is difficult to determine the actual value of surface area of CF fabric anode so only the trend can be shown. The circuit resistance of carbon fibre fabric 6 anode increased moderately from $36.5 \mathrm{k} \Omega \cdot \mathrm{m}^{2}$ to $420 \mathrm{k} \Omega \cdot \mathrm{m}^{2}$ after 575 hours of exposure and then kept remaining the same at this value.

3.2.2. Test for Carbon Fibre Anodes with respect to the Electrical Conductivity of the Bonding Medium. Specimens 4.1 consisted of CF fabric bonded to the surface and $4.2 \mathrm{a}$ of a CF rod bonded into pre-formed grooves of the beams using epoxy. $\mathrm{CP}$ was applied to the reinforced concrete prism with the CF fabric or rod employed as the anode. The CP was applied 7 days after the application of the CF anodes to the concrete prisms.

The observed current passing to the CFRP fabric demonstrated that the CF fabric with epoxy had sufficient electrical conductivity to operate as an anode (Figure 11(a)). However, there was no current passing through the CF rod, demonstrating that the combination of CF rod and epoxy is not sufficiently conductive (Figure 10(a)). In order to correct this problem a number of alternatives were considered, such as adding carbon powder to the epoxy to increase electrical conductivity, using a combination of fabric with rod either by wrapping or lining the slot before embedding the rod in epoxy, and using a geopolymer or high strength cementitious grout in place of the epoxy.

The test was repeated with geopolymer and chopped CF fabric. This aimed to both increase the electrical conductivity and control the shrinkage of the geopolymer during curing. The CP current was then applied to the small scale CF anode specimen (Figure 11(b)). The applied current versus exposure time of CF fabric anode + epoxy (Specimen 4.1) and CF rod anode + geopolymer (Specimen $4.2 \mathrm{c}$ ) is plotted in Figure 12 and their circuit resistance and exposure time relationship is shown in Figure 13.

Figure 12 shows that the current passing to the epoxy bonded CF fabric anode reduced steadily from $5 \mathrm{~mA}$ to $1 \mathrm{~mA}$ (corresponding to $64 \mathrm{~mA} / \mathrm{m}^{2}$ of steel area) after 385 hours of operation. This current of $1 \mathrm{~mA}$ remained constant for a further 264 hours (total duration 649 hours). There was an increase in current after 24 hours of exposure which may be due to the surrounding environment increasing the resistivity of the concrete electrolyte. The current passing to the geopolymer supported CF rod anode decreased from $19 \mathrm{~mA}$ to the stable value of $1 \mathrm{~mA}$ (corresponding of $64 \mathrm{~mA} / \mathrm{m}^{2}$ of steel area) after 171.5 hours of operation. The test continued for a further 44.5 hours (total duration 216 hours). There was no sign of damage at concrete-CF rod interface.

Figure 13 shows that the circuit resistance of $\mathrm{CF}$ fabric anode increased considerably in 385 hours from $168 \mathrm{k} \mathrm{Ohms} \cdot \mathrm{m}^{2}$ to $840 \mathrm{kOhms} \cdot \mathrm{m}^{2}$ and stayed at this value for the remaining time of exposure. This indicates that over long periods of operation, the dissolution of CF fabric would appear to be very small and may be tolerable. The CF fabric anode subject to a current of $1 \mathrm{~mA}$ and applied voltage of $5 \mathrm{~V}$ showed some limited generation of yellow liquid and gaseous deposits at the concrete-fabric interface.

\subsubsection{Polarization of Steel of Small Beams with ICCP Carbon} Fibre Anodes. During the 1100 hours of operation of the ICCP, the on and instant-off potential values of all the steel bars of small beams (CFF1, CFF2, CFR1, and CFR3) were recorded. The potential decays were monitored and are plotted in Figure 14. Based on this data, the potential decays are more than $150 \mathrm{mV}$ after 4 hours of monitoring. This demonstrates that CP of the embedded steel has been successfully achieved in accordance with the recommendations in Concrete Society Technical Report number 73 [22]. 

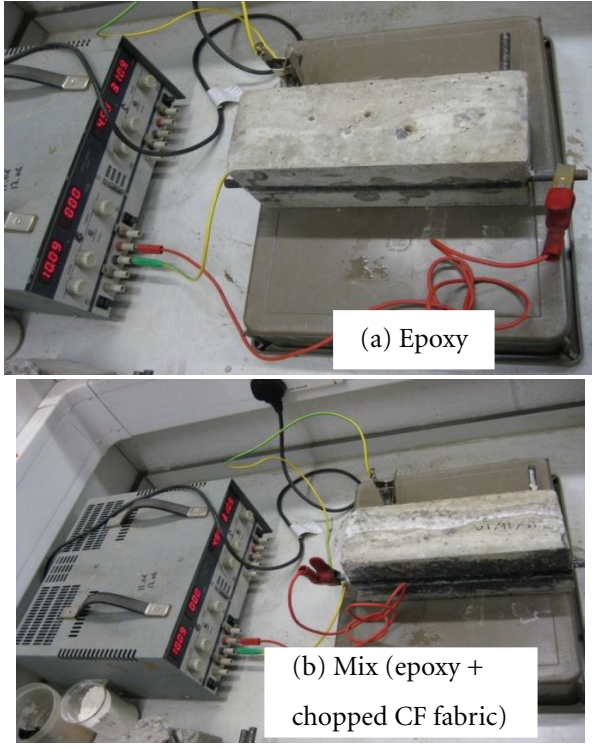

FIgURE 10: Bonding CF rod to grooved concrete prism using (a) epoxy (4.2a) and (b) epoxy plus chopped CF fabric (4.2b).

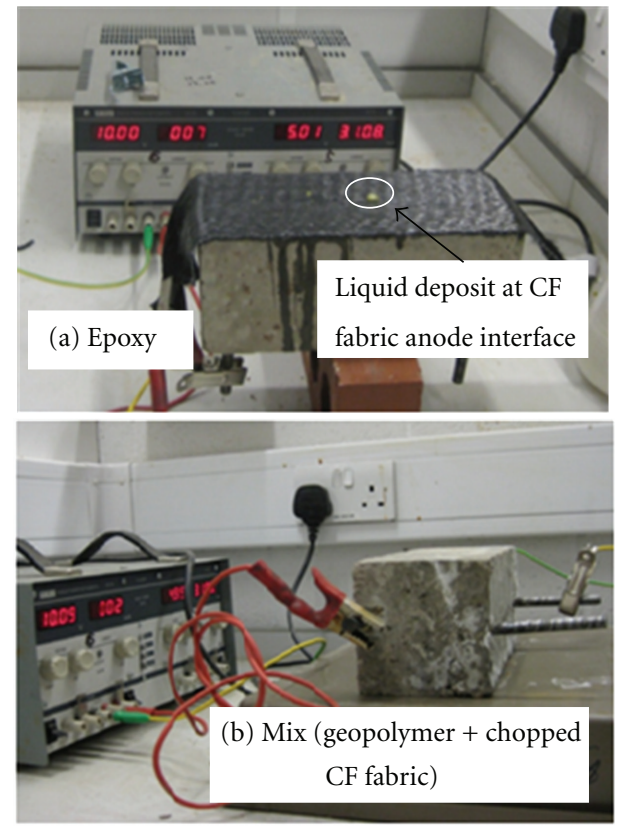

FIGURE 11: The performance of CF fabric anode bonded to concrete surface by epoxy (4.1) and CF rod anode bonded to grooved concrete by geopolymer plus chopped CF (4.2c).

\section{Conclusion}

This preliminary study into the electrical conductivity and potential use of carbon fibre fabric and rod as an anode in impressed current cathodic protection has produced the following conclusions.

(i) The anode current decreased with increasing exposure time. This is attributed to dissolution of the $\mathrm{CF}$ anode which results in an increase in the $\mathrm{CP}$ circuit

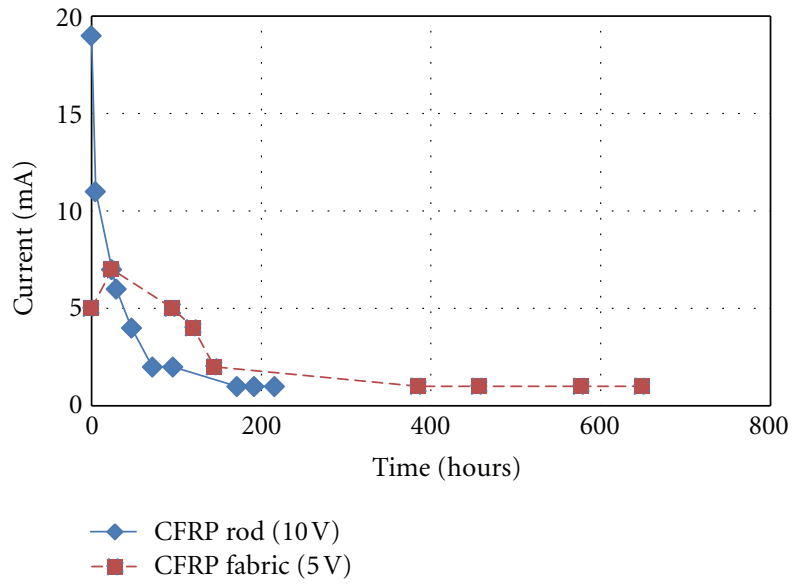

Figure 12: Applied current versus exposure time (4.1 and 4.2c).

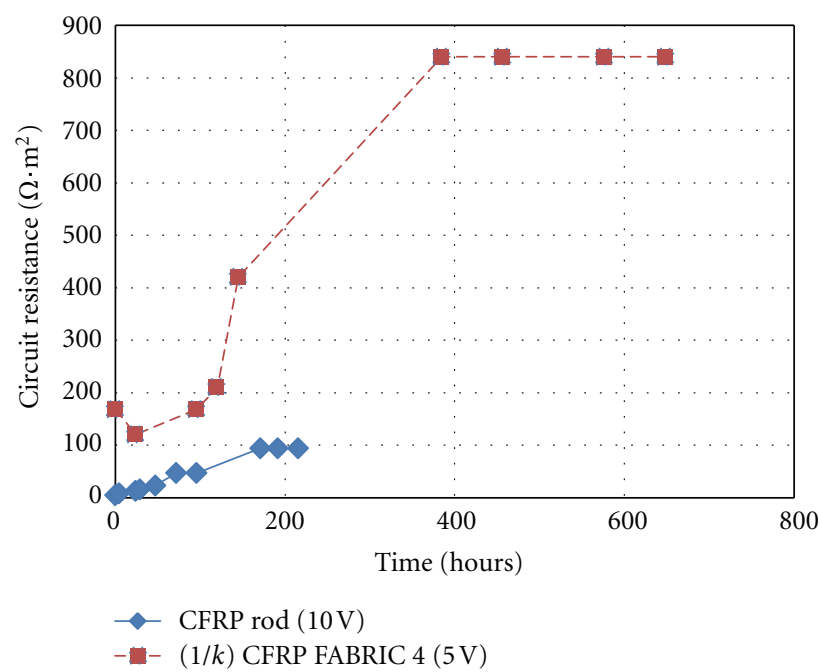

FIGURE 13: Circuit resistance versus exposure time (4.1 and 4.2c).

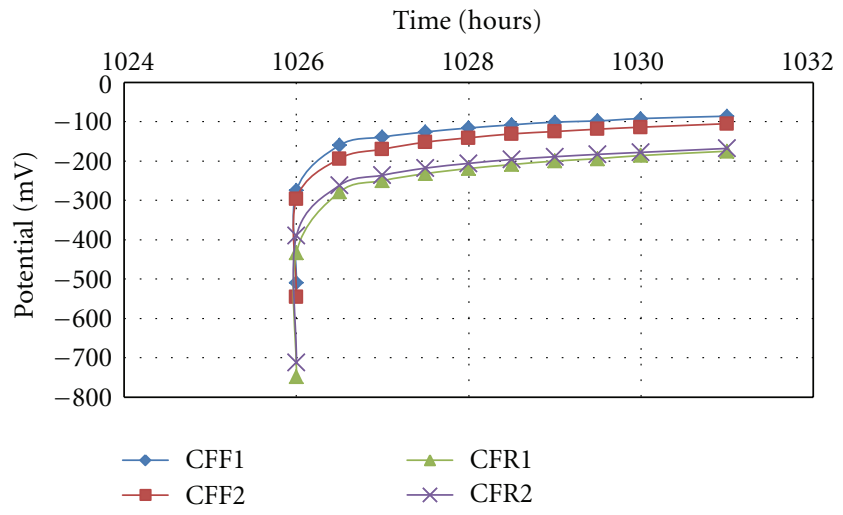

Figure 14: Potential decays of reinforcing steel specimens [22].

resistance. The rate of consumption of $\mathrm{CF}$ anodes is relatively low. However, CF may be susceptible to damage after employment as an anode of CP.

(ii) Acidic deposits can be generated at the CF anodeconcrete interface. 
(iii) Epoxy can be used to bond CF fabric anode to concrete surfaces.

(iv) Epoxy is not suitable for bonding CF rod anode into concrete because of the high resistivity of the epoxy. As a result there is no current passing through the CF anode.

(v) Geopolymer with chopped carbon fibre modification can be used to replace epoxy to bond CF rod anodes to concrete.

(vi) CF can be employed effectively as an anode for ICCP. $\mathrm{CF}$ rod anode is capable of operating at more than $64 \mathrm{~mA} / \mathrm{m}^{2}$ of reinforcing steel area without significant signs of damage or debonding. CF fabric anode can operate at $128 \mathrm{~mA} / \mathrm{m}^{2}$ of steel area with small liquid deposit generated on the surface.

\section{References}

[1] US Federal Highway Administration, Memorandum on FHWA Position on Cathodic protection Systems, 1982.

[2] P. Pedeferri, "Cathodic protection and cathodic prevention," Construction and Building Materials, vol. 10, no. 5, pp. 391402, 1996.

[3] P. Lambert, "Cathodic protection of reinforced concrete," Anti-Corrosion Methods \& Materials, vol. 42, no. 4, pp. 4-5, 1995.

[4] C. H. Haldemann and A. Schreyer, "Ten years of Cathodic protection in Concrete in Switzerland," Corrosion of Reinforcement in Concrete: Monitoring, Prevention and Rehabilitation papers from Eurocorr '97, European Federation of Corrosion Publication No.25. London, UK, Institute of Materials, 1998.

[5] G. Mays, "Durability of Concrete Structures: Investigation, Repair, Protection," Pub: E\& FN Spon, 1992.

[6] R. L. Kean and K. G. Davies, Cathodic Protection, DTI Publication, 1981.

[7] L. Bertolini, F. Bolzoni, P. Pedeferri, L. Lazzari, and T. Pastore, "Cathodic protection and cathodic prevention in concrete: principles and applications," Journal of Applied Electrochemistry, vol. 28, no. 12, pp. 1321-1331, 1998.

[8] S. Szabó and I. Bakos, "Cathodic protection with sacrificial anodes," Corrosion Reviews, vol. 24, no. 3-4, pp. 231-280, 2006.

[9] S. Szabó and I. Bakos, "Impressed current cathodic protection," Corrosion Reviews, vol. 24, no. 1-2, pp. 39-62, 2006.

[10] J. P. Broomfield and S. El-Belbol, "Impressed Current Anodes for the Cathodic Protection of Atmospherically Exposed Reinforced Concrete," CPA, Technical Note no.11, 2011.

[11] X. Shi, J. D. Cross, L. Ewan, Y. Liu, and K. Fortune, "Replacing Thermal Sprayed Zinc Anodes on Cathodically Protected Steel Reinforced Concrete Bridges," Final Report, SPR 682, 2011.

[12] The Concrete Society, "Cathodic protection of steel in concrete," Tech. Rep. 73, 2001.

[13] B. S. Covino Jr., S. D. Cramer, S. J. Bullard et al., "Performance of Zinc Anode for Cathodic Protection of Reinforced Concrete Bridges," Final Report, SPR 354, 2002.

[14] J. F. Bonacci and M. Maalej, "Externally bonded fiberreinforced polymer for rehabilitation of corrosion damaged concrete beams," ACI Structural Journal, vol. 97, no. 5, pp. 703-711, 2000.

[15] The Concrete Society, "Design guidance for strengthening concrete structures using fibre composite materials, 3rd ed." Tech. Rep. 55, 2012.
[16] M. Z. Jumaat, M. H. Kabir, and Obaydullah, "A review of the repair of reinforced concrete beams," Journal of Applied Science Research, vol. 2, no. 6, pp. 317-326, 2006.

[17] S. Gadve, A. Mukherjee, and S. N. Malhotra, "Corrosion of steel reinforcements embedded in FRP wrapped concrete," Construction and Building Materials, vol. 23, no. 1, pp. 153$161,2009$.

[18] E. W. Berver, D. W. Fowler, and J. J. King, "Corrosion in FRPwrapped concrete members," in Structural Faults and Repair, 2001.

[19] L. K. Spainhour, I. A. Wootton, and N. Yazdani, "Effect of composite fibre wraps on corrosion of reinforced concrete columns in a simulated splash zone," in Proceedings of the 3 rd International Conference on Composites in the Infrastructure, San Francisco, Calif, USA, June 2002.

[20] A. S. Debaiky, M. F. Green, and B. B. Hope, "Corrosion evaluation in CFRP wrapped RC," in Proceedings of the 9th International Conference \& Exihibition on Structural Fualts and Repair, Kensington, UK, 2001.

[21] C. Lee, J. F. Bonacci, M. D. A. Thomas et al., "Accelerated corrosion and repair of reinforced concrete columns using carbon fibre reinforced polymer sheets," Canadian Journal of Civil Engineering, vol. 27, no. 5, pp. 941-948, 2000.

[22] C. V. Nguyen, P. S. Mangat, P. Lambert, F. J. O'Flaherty, and G. Jones, "Dual function carbon fibre strengthening and cathodic protection anode for reinforced concrete structures," in Concrete Repair, Rehabilitation and Retrofitting III, Alexander, Ed., pp. 1179-1185, Taylor \& Francis Group, London, UK, 2012. 

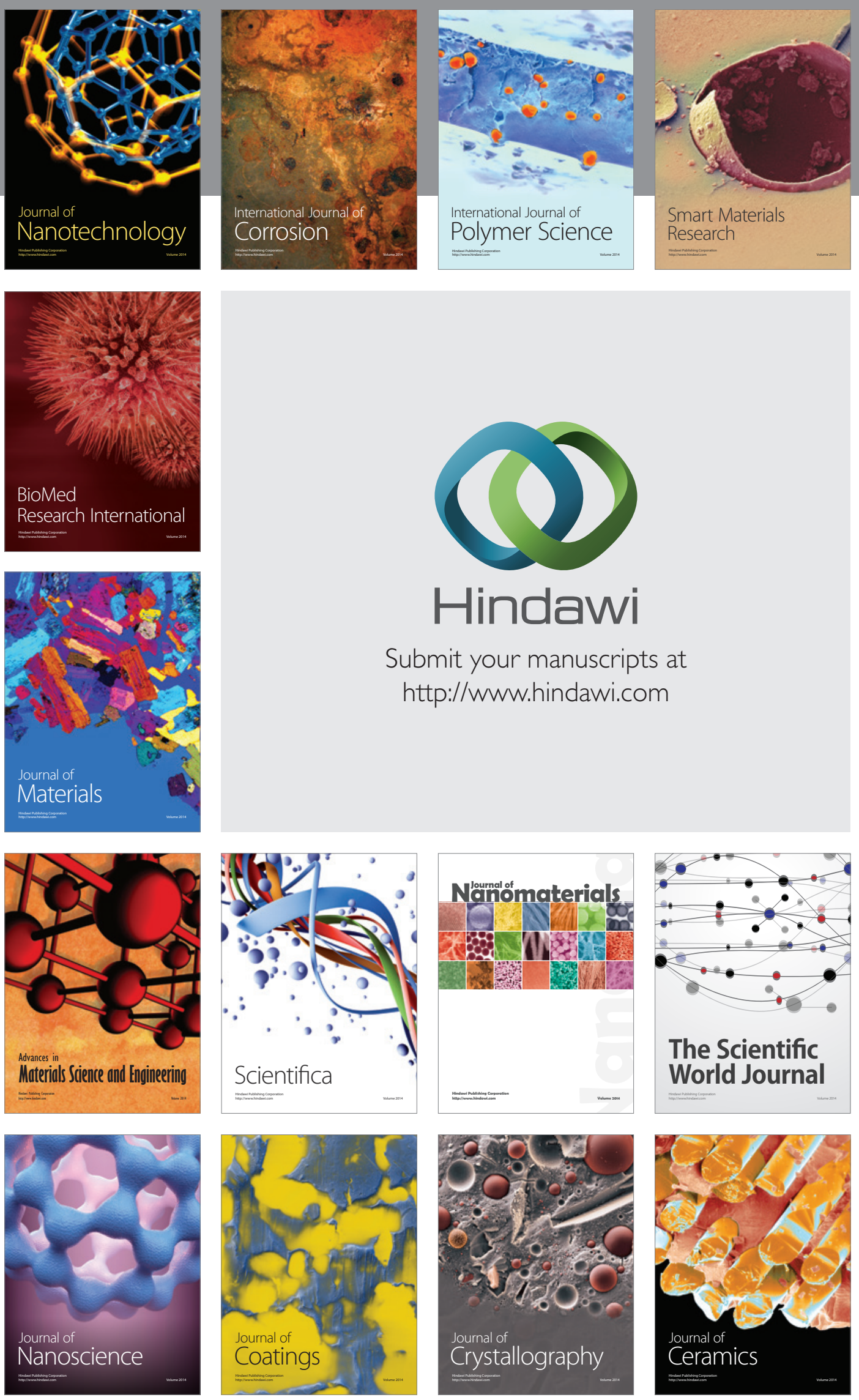

The Scientific World Journal

Submit your manuscripts at

http://www.hindawi.com

\section{World Journal}

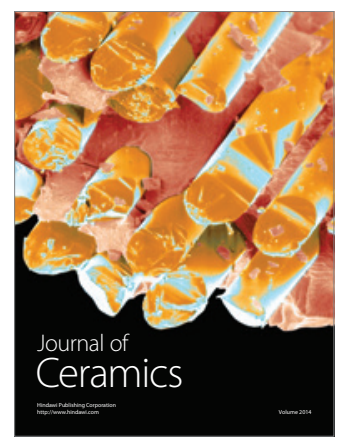

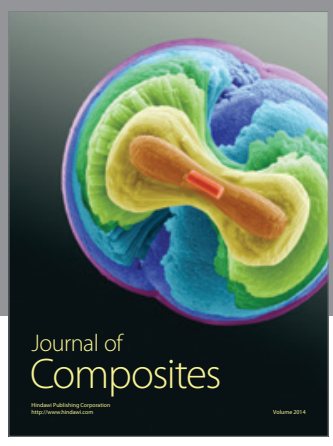
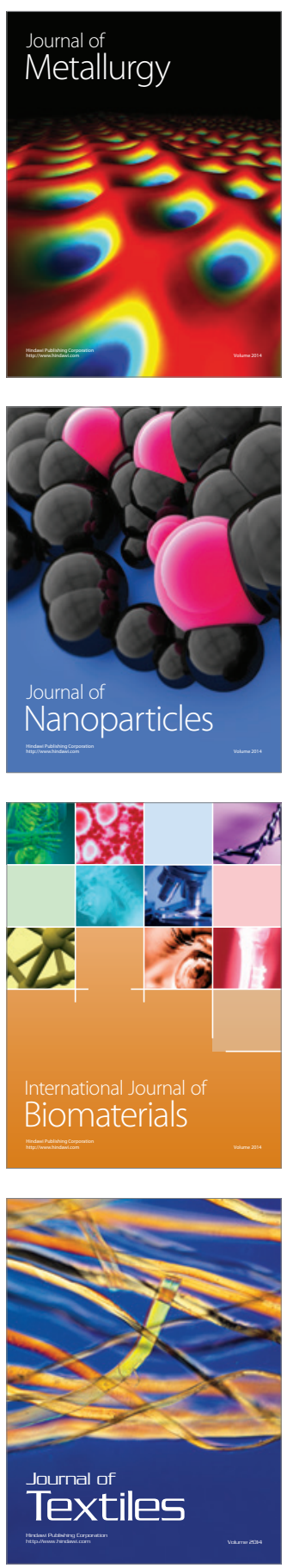